\title{
Developmental Toxicity of Ethanolic Extracts of Leaves of Achyranthes aspera, Amaranthaceae in Rat Embryos and Fetuses
}

\author{
Daniel Teshome (iD) \\ Chalachew Tiruneh (iD) \\ Leykun Berhanu iD ${ }^{2}$ \\ Gete Berihun (iD ${ }^{2}$ \\ Zebader Walle Belete (iD ${ }^{3}$ \\ 'Department of Anatomy, College of \\ Medicine and Health Sciences, Wollo \\ University, Dessie, Ethiopia; ${ }^{2}$ Department \\ of Environmental Health, College of \\ Medicine and Health Sciences, Wollo \\ University, Dessie, Ethiopia; ${ }^{3}$ Department \\ of Public Health, College of Health \\ Sciences, Debre Tabor University, Debre \\ Tabor, Ethiopia
}

Correspondence: Daniel Teshome Department of Anatomy, College of Medicine and Health Sciences, Wollo University, PO. Box I I45, Dessie, Ethiopia Tel +251919158464

Email danigreatt19@gmail.com
Introduction: Achyranthes aspera is one of the medicinal plants widely used for fertility control in the local health system of Ethiopia.

Objective: Assessment of developmental toxicity of ethanolic extracts of leaves of Achyranthes aspera in rat embryos and fetuses.

Methods: Fresh leaves were extracted by mixing the grinded powder with $70 \%$ ethanol. Then, the extract was given orally to gravid Wistar rats at doses of $250 \mathrm{mg} / \mathrm{kg}, 500 \mathrm{mg} / \mathrm{kg}$ and $1000 \mathrm{mg} / \mathrm{kg}$ from day 6-12 of gestation. On gestational days 12 and 20, embryos and fetuses were examined for developmental and gross malformations.

Results: On day 12 embryos, the number of implantation sites and somites in $1000 \mathrm{mg} / \mathrm{kg}$ treated rats were significantly reduced. The number of implantation sites in pair-fed control and $1000 \mathrm{mg} / \mathrm{kg}$ groups was $11.2 \pm 0.86$ and $8.34 \pm 0.65$, respectively. Retarded development of hindlimb, forelimb, optic and olfactory systems was detected at a high dose. In addition, the number of branchial bar was significantly reduced in $1000 \mathrm{mg} / \mathrm{kg}$ dose. In near-term fetuses, significant reduction of litter weight and crown-rump length was seen at $1000 \mathrm{mg} / \mathrm{kg}$ dose. Crown-rump length in pair-fed control and $1000 \mathrm{mg} / \mathrm{kg}$ treated groups was $2.82 \pm 0.17 \mathrm{~cm}$ and $2.31 \pm 0.11 \mathrm{~cm}$, respectively. Fetal resorptions and deaths in $1000 \mathrm{mg} / \mathrm{kg}$ were $1.45 \pm 0.65$ and 0.81 \pm 0.67 , respectively. However, external anomalies were not detected for all offspring at all doses. Conclusion: The finding suggests that ethanolic leaf extracts of A. aspera have detrimental effects on the development of rat embryos and fetuses at a higher dose. The possible teratogenic effects were indicated with the substantial retardation in embryonic and fetal development, decrease in number of implantation sites and rise in fetal resorptions and death. Moreover, it resulted in significant reduction in litter weight and crown-rump length at a higher dose.

Keywords: Achyranthes aspera, toxicity, Wistar rat, embryo, fetus

\section{Introduction}

The utilization of traditional medicine and provision for therapeutic usage has been gaining popularity all over the world. ${ }^{1}$ Herbal medicines are used by about $85 \%$ of the world's population for disease prevention and management, and their use is growing all over the world. ${ }^{2}$ In developing countries, utilization of traditional plants for therapeutic purposes has very important significance. In such countries, traditional medicinal plants are typically the preferred, accessible and inexpensive management because hospitals and/or local health centers provide inadequate medical care and/or there is no well developed health care system. ${ }^{3}$ This is valid, 
for example, in some Latin American and African countries where provision of health care is not accessible for all communities. $^{3-7}$

In Ethiopia, where advanced public health facilities are limited and inaccessible, herbal medicine has been used by $80 \%$ of the community for primary health care. Traditional medical services are also practiced in Ethiopian cities, where interventional services are more commonly accessible, and contribute significantly to the country's public health care system, especially in Addis Ababa. ${ }^{8}$

Herbal medicinal plants are differentiated by their variety in terms of plant species used. Achyranthes aspera Linn. is one medicinal plant widely used for fertility control in the local health system of Ethiopia. It belongs to the family Amaranthaceae and is usually scattered as a wild plant all the way through the tropical and subtropical regions. ${ }^{9}$

It is a long-lived (perennial) erect or spreading herb that can reach a height of $2 \mathrm{~m}$. At the root, the stems become woody. Its opposite, simple, egg-shaped leaves can reach a length of $10 \mathrm{~cm}$ with $8 \mathrm{~cm}$ width. $A$. aspera is a variable species divided into six varieties, two of which have been documented from East Africa: A. aspera var. aspera has a long perianth and pointed leaves, while $A$. aspera var. indica has a short perianth and blunt leaves. ${ }^{10}$

In various parts of the world, the plant is known by different names. In Amharic, it is known as "Telenge" or "Ambulale", and in English it is known as "Prickly-Chaff" or "Devil's Horsewhip". 9

The leaves of $A$. aspera mainly contain hydroquinone (57.7\%) followed by p-benzoquinone, spathulenol, nerol, $\alpha$-ionone, asarone and eugenol. ${ }^{11} \mathrm{~A}$ study conducted on phytochemical screening of methanolic leaf extract using chemical tests demonstrates the presence of saponins, tannis, polyphenolic glycosides, flavonoids, alkaloids and phytosteroidal compounds. ${ }^{12,13}$

In tropical Asia and Africa, the plant is used as a folk remedy in traditional medical systems. The leaves of $A$. aspera have been used in the treatment of pyrexia, wound healing, tooth pain, inflammation of joints, gynecological disorders, renal disorders, insect and snake bites, abdominal tumor, dyspepsia and a number of other ailments. ${ }^{14-16}$ Furthermore, different plant parts have been used to treat various illnesses such as tonsillitis, head wounds and ringworm. ${ }^{17,18}$

Several studies reveal that the leaves of $A$. aspera have antifungal, hepatoprotective, antidiabetic, hypolipidemic, antioxidant, anticataract, antinociceptive and antimicrobial properties. ${ }^{19-25}$ And also, its leaf has abortifacient, diuretic, antidepressant, molluscidal and spermicidal effects. ${ }^{26-30}$ Different parts of the plant extracts have been used for contraception, placental retention and postpartum bleeding. ${ }^{31}$

The anti-implantation effect of the $A$. aspera root was found to be $83.3 \%$ at a dose of $200 \mathrm{mg} / \mathrm{kg}$ body weight in a report on post-coital antifertility activity. As the rat progressed through the gestation, there was a high occurrence of fetal mortality near full term. As a result, the antifertility (anti-implantation and abortifacient) efficacy of the ethanolic extracts of $A$. aspera root is $100 \%{ }^{32}$

The use of $A$. aspera has been studied and published extensively. ${ }^{33}$ However, no research has been reported on the developmental toxicity of $A$. aspera leaves yet. As a result, the current study will look into the potential toxicity of $A$. aspera leaves in rat embryos and fetuses.

\section{Methods and Materials Experimental Design}

In vivo experiment was intended to evaluate the developmental toxicity of $A$. aspera in nulliparous female Wistar albino rats. It was conducted on 12-day-old embryos (Day12 experiment) and 20-day-old fetuses (Day-20 experiment).

\section{Plant Materials Collection and Processing}

Leaves of A. aspera were collected from a location near Fiche Town in central Ethiopia in March 2020. A taxonomist identified the plant, and the voucher sample (AA-2135) was deposited in the herbarium for future use. Fresh leaves were dried under shade, ground into a coarse powder and mixed with $70 \%$ ethanol for 24 to 48 hours. It was then filtered using filter paper (Whatman No. 1). A rotary evaporator was used to dissolve the solvent. The extract was concentrated further in a water bath at $40^{\circ} \mathrm{C}$ by heating and evaporating the solvent. A total of $1 \mathrm{~kg}$ dry leaf was dissolved in 5 liters of $70 \%$ ethanol in a 1 to 5 ratio to produce $165.12 \mathrm{~g}(17.26 \%)$ crude extract. Then, the dried extract was placed in a firmly preserved container at $-20^{\circ} \mathrm{C}$ until use. ${ }^{34}$

\section{Experimental Animals}

The experiments used Wistar albino rats: 25 male rats aged 3 months, and 50 female rats aged 12-14 weeks. The rats were sourced from the EPHI's experimental animal breeding facility. All of the animals were kept in standard cages with consistent lighting and were kept at room temperature. Pellets and tap water were readily 
accessible to the animals. The animals were handled according to the International Guidelines for the Care and Use of Laboratory Animals. After five days of acclimatization, the animals were mated overnight by placing male rats into a cage with two nulliparous female rats in 1:2 ratios. The next morning, the female rats were examined for a copulatory plug, and vaginal smears were taken for microscopic analysis of spermatozoa. Day 0 of pregnancy was defined as the presence of spermatozoa in a vaginal smear. ${ }^{35}$

\section{Grouping and Dosing of Pregnant Rats}

Gravid rats were randomly assigned into four groups, each with five animals: three experimental and one control. The pair-fed control group, Group I, was treated with distilled water. Groups II, III and IV were provided ethanolic leaf extracts of A. aspera at doses of $250 \mathrm{mg} /$ $\mathrm{kg}, 500 \mathrm{mg} / \mathrm{kg}$ and $1000 \mathrm{mg} / \mathrm{kg}$, respectively. Animals were given a different dose of $A$. aspera extracts for a week, from day 6 to day 12 of gestation, since this is when embryogenesis and organogenesis are most involved. The $A$. aspera extract doses were chosen based on prior findings of acute toxicity studies. ${ }^{36}$ The extract was measured, combined with distilled water and vortex-shaken continuously. With distilled water, the final amount was $2 \mathrm{~mL} / 100 \mathrm{~g}$, and oral gavage was used for administration. ${ }^{35}$ Each animal in the experimental groups (Groups II, III and IV) received an equal amount of the control diet. Except for the A. aspera leaf extracts, which were given only to the experimental groups, the pair-fed control group had the same diet and was held in the same setting as the experimental groups. Every animal's daily food intake was reported every morning, and their weight was documented on days 0 , 6 and 12 of pregnancy for day-12 experiment and days 0 , 6,12 and 20 of gestation for day-20 experiment. ${ }^{37}$

\section{Day-12 Achyranthes aspera Leaf Extracts Experiment}

The purpose of the study was to see whether $A$. aspera could cause toxicity on day-12 rat embryos. The experiment was intended to reveal any birth defects that may not have been visible on day 20 fetuses due to potential compensatory growth and development.

Gravid rats were allowed to lose their consciousness by cervical dislocation on day 12 of gestation, at noon. The rats were then put on an operating table in a supine position. The limbs were extended and fixed, and an abdominal mid-sagittal skin incision was used to open the abdominal cavity. Both sides' skin flaps and abdominal muscles were mirrored laterally and secured with pins. After that, Hank's balanced salt solution was used to dissolve the uterine horns. The embryos were then exposed by incising the uterine horns along the antimesometrial border. ${ }^{37}$ To reveal the underlying visceral yolk sac, the membranes covering the embryos were cut with fine forceps and a dissecting microscope. The circulation and growth of the yolk sac were studied. Then, the embryos were explanted and the developments of all systems were quantified using Brown and Fabro parameters, which included 16 recognizable developmental endpoints. Moreover, the numbers of somites, implantations and resorptions sites were counted. ${ }^{38}$

\section{Day-20 Achyranthes aspera Leaf Extracts Experiment}

The purpose of this study was to see whether $A$. aspera had any toxic effects on 20-day-old rat fetuses. Pregnant rats were euthanized by cervical dislocation on day 20 of gestation. The procedure for dissecting pregnant rats was similar to that of the day-12 experiment. The uterine horns were exposed and examined intact.

The number of implantation sites was determined by counting the metrial glands, which are yellowish nodules, located along the mesometrial margin of the uterine horns. The metrial nodules, which were not occupied by living or recently dead fetuses, represented the number of prior resorptions. The numbers of live or dead fetuses were determined by applying gentle pressure on them. The uterine horns were incised along the anti-mesometrial border to reveal the fetuses, fetal membranes and placenta. Fetuses were then recovered and dissected free of the placenta. The crown-rump length (CRL) was measured from the top of the head (crown) to the bottom of the buttocks. Moreover, placental weights were recorded. Following these measurements, the fetuses were fixed in Bouin's solution (aqueous saturated solution of picric acid $75 \%$, formalin $25 \%$ and glacial acetic acid 5\%) for gross external examination. ${ }^{37}$

\section{Gross Evaluation}

The fetuses were observed using dissecting microscope, from head to tail for gross anomalies. The following parameters were examined: 
(i) Craniofacial development

(ii) Limb development

(iii) The vertebral column

(iv) Tail development

(v) External genitalia

\section{Data Analysis}

Epi-info version 7.1 was used to clean, code and enter data, which were then exported to SPSS version 20 for analysis. The data were presented as mean and standard deviation. One-way ANOVA was used to compare between and within groups, followed by Tukey's post hoc multiple comparison test. When the $p$-value was less than 0.05 , the findings were considered as statistically significant.

\section{Results}

\section{Day-12 Achyranthes aspera Leaf Extracts Experiment}

\section{Maternal Weight Gain, Daily Food Intake and} Outcomes of Pregnancy

The maternal weight gain of the pair-fed control group and the $1000 \mathrm{mg} / \mathrm{kg}$ Achyranthes aspera leaf extract treated group was $6.23 \pm 0.34 \mathrm{~g}$ and $5.62 \pm 0.42 \mathrm{~g}$, respectively. The maternal weight gain was reduced in a dose-dependent manner, but it was not statistically significant. On days $1-5$ and $6-12$, there was no significant difference in daily food consumption between the groups. Regarding the implantation sites, there was significant reduction in implantation sites in the $1000 \mathrm{mg} / \mathrm{kg}$ treated group as compared to pair-fed control and $250 \mathrm{mg} / \mathrm{kg}$ treated groups. Furthermore, as compared to the pair-fed control and $250 \mathrm{mg} / \mathrm{kg}$ treated groups, the number of resorption sites in the $1000 \mathrm{mg} / \mathrm{kg}$ A. Aspera leaf extract treated group was significantly higher (Table 1 ).

\section{Growth of the Embryo}

The number of somites and morphological scores were used to assess the embryo's development. In the pair-fed control and $1000 \mathrm{mg} / \mathrm{kg}$ treated groups, the number of somites was $29.25 \pm 0.64$ and $26.47 \pm 0.78$, respectively. When compared to pair-fed control and $250 \mathrm{mg} / \mathrm{kg}$ treated groups, it was slightly lower in $1000 \mathrm{mg} / \mathrm{kg}$ treated group. The pair-fed control and $1000 \mathrm{mg} / \mathrm{kg}$ treated groups had morphological scores of $42.31 \pm 1.89$ and $40.35 \pm 1.56$, respectively. When compared to pair-fed control and $250 \mathrm{mg} / \mathrm{kg}$ treated groups, it was slightly lower in $1000 \mathrm{mg} / \mathrm{kg}$ treated group (Table 2).

\section{Embryonic Development}

Brown and Fabro's morphological score was used to evaluate the embryo's development. ${ }^{38}$ The number of embryos was reduced in a dose-dependent manner, but this was not statistically significant. In terms of yolk sac circulation, the $1000 \mathrm{mg} / \mathrm{kg}$ group had a full plexus of vessels in the yolk sac. The yolk sac circulation was obliterated in the pair-fed control group, and the vitelline artery and vein were well divided. The embryo was dorsally convex in the $1000 \mathrm{mg} /$ $\mathrm{kg}$ treated group, but dorsally convex with spiral torsion in pair-fed control group. In all groups, the atrial commune, ventricular commune and bulbus cordis were noticeable and separated. There was no substantial difference between the groups. The posterior neuropore was fully closed in pair-fed control group, but not in the $1000 \mathrm{mg} /$ $\mathrm{kg}$ treated group.

In terms of hindbrain development, pronounced pontine flexure with transparent roof of fourth was visible in the pair-fed control group, but anterior neuropore was closed and rhombencephalon was developed in the $1000 \mathrm{mg} / \mathrm{kg}$ treated group. The mesencephalon was fully fused in the high dose treated group, while the separation

Table I Maternal Weight Gain, Daily Food Intake and Outcomes of Pregnancy After Administration of Ethanolic Leaf Extracts of Achyranthes aspera on Day-12 Experiment

\begin{tabular}{|l|l|l|l|l|l|}
\hline \multirow{2}{*}{ Groups } & \multicolumn{2}{|l|}{$\begin{array}{l}\text { Maternal Weight Gain } \\
\text { Per Dam (g) }\end{array}$} & \multicolumn{2}{|l|}{ Daily Food Intake (g/Day) } & \multicolumn{2}{l|}{ Outcomes of Pregnancy } \\
\cline { 2 - 6 } & & Day I-5 & Day 6- I 2 & Implantation Sites Per Litter & Resorptions Per Litter \\
\hline G-I & $6.23 \pm 0.34$ & $14.82 \pm 0.43$ & $15.94 \pm 0.23$ & $11.2 \pm 0.86$ & $0.56 \pm 0.31$ \\
G-II & $5.9 I \pm 0.81$ & $14.77 \pm 0.44$ & $15.92 \pm 0.24$ & $11.4 \pm 0.82$ & $0.58 \pm 0.43$ \\
G-III & $5.78 \pm 0.53$ & $14.75 \pm 0.41$ & $15.8 I \pm 0.21$ & $10.23 \pm 0.57$ & $0.67 \pm 0.48$ \\
G-IV & $5.62 \pm 0.42$ & $14.8 I \pm 042$ & $15.78 \pm 0.31$ & $8.34 \pm 0.65^{\mathrm{a}}$ & $0.9 \pm 0.37^{\mathrm{a}}$ \\
F statistics & 26.2 & 3.02 & 9.21 & 2.23 & 6.26 \\
P value & 0.07 & 0.21 & 0.07 & 0.02 & 0.021 \\
\hline
\end{tabular}

Notes: Results are summarized as mean \pm SDM. ${ }^{a}$ Significantly different $(p<0.05)$ from pair-fed control and $250 \mathrm{mg} / \mathrm{kg}$ treated groups. 
Table 2 Growth of the Embryo After Administration of Ethanolic Leaf Extracts of Achyranthes aspera on Day-12 Experiment

\begin{tabular}{|l|c|c|}
\hline \multirow{2}{*}{ Groups } & \multicolumn{2}{|c|}{ Growth of the Embryo } \\
\cline { 2 - 3 } & Number of Somites & Morphological Score \\
\hline G-I & $29.25 \pm 0.64$ & $42.31 \pm 1.89$ \\
G-II & $29.33 \pm 0.72$ & $42.75 \pm 1.92$ \\
G-III & $28.89 \pm 0.34$ & $41.73 \pm 1.48$ \\
G-IV & $26.47 \pm 0.78^{\mathrm{a}}$ & $40.35 \pm 1.56^{\mathrm{a}}$ \\
F statistic & 48.21 & 13.21 \\
P value & 0.03 & 0.013 \\
\hline
\end{tabular}

Notes: Results are summarized as mean \pm SDM. ${ }^{\text {a }}$ Significantly different $(p<0.05)$ from pair-fed control and $250 \mathrm{mg} / \mathrm{kg}$ groups.

between the mesencephalon and diencephalon was evident in pair-fed control group. In the $1000 \mathrm{mg} / \mathrm{kg}$ treated group, telencephalic evagination was visible, while in the pair-fed control group the telencephalic hemisphere was well elevated. There was slight delay in the development of hindbrain, midbrain and forebrain but not statistically significant. The otocyst was observed in a high dose treated group during otic system development, while the otocyst with dorsal recess was visible in all other groups. The $500 \mathrm{mg} / \mathrm{kg}$ and $1000 \mathrm{mg} / \mathrm{kg}$ treated groups had elongated optic primordium, while the pair-fed control and $250 \mathrm{mg} /$ $\mathrm{kg}$ treated groups had primary optic vesicles with open optic stalks. The olfactory plate was seen in the pair-fed control and $250 \mathrm{mg} / \mathrm{kg}$ treated groups, but not in the high dose treated group. Only branchial bars I and II were visible in the $1000 \mathrm{mg} / \mathrm{kg}$ treated group, while branchial bars I, II and III were visible in the pair-fed control group.

In a high dose treated group, the maxillary process was separated from the nasal process by a visible cleft anterior to bar I, while in all other groups the maxillary process was merged with the nasal process. In the $1000 \mathrm{mg} / \mathrm{kg}$ treated group, there was no sign of mandibular development from bar I. However, in the pair-fed control and $250 \mathrm{mg} / \mathrm{kg}$ treated groups, the first branchial bar was fused and formed the mandibular process. In high dose treated groups, there was a distinct evagination of the Wolffian crest at the level of somites 9-13. The other groups, however, had forelimb buds. In terms of hindlimb development, high dose treated groups showed discrete evagination of the Wolffian crest at the level of somites 26-30, but all other groups showed hindlimb bud (Table 3).

\section{Day-20 Achyranthes aspera Leaf Extracts Experiment Daily Food Intake and Maternal Weight Gains} In the pre-treatment and treatment period there was no significant difference in maternal daily food intake. However, the maternal food consumption was reduced in

Table 3 In vivo Development of Rat Embryo After Treatment with Achyranthes aspera Leaf Extracts on Day-12 Experiment

\begin{tabular}{|l|c|c|c|c|}
\hline \multirow{2}{*}{ Morphological End Point } & \multicolumn{3}{|c|}{ Groups } \\
\cline { 2 - 5 } & G-I & G-II & G-III & G-IV \\
\hline Number of embryos & $4 I$ & 42 & 40 & 38 \\
Yolk sac circulation & $3.65 \pm 0.32$ & $3.33 \pm 0.43$ & $3.36 \pm 0.5$ & $3.04 \pm 0.42^{\mathrm{a}}$ \\
Flexion & $2.64 \pm 0.5$ & $2.56 \pm 0.49$ & $2.43 \pm 0.47$ & $2.34 \pm 0.38$ \\
Heart & $3.54 \pm 0.49$ & $3.45 \pm 0.54$ & $3.42 \pm 0.45$ & $3.37 \pm 0.46$ \\
Caudal Neural Tube & $4 \pm 0.00$ & $3.93 \pm 0.13$ & $3.89 \pm 0.23$ & $3.87 \pm 0.21$ \\
Hind brain & $3.91 \pm 0.5$ & $3.85 \pm 0.48$ & $3.73 \pm 0.42$ & $3.43 \pm 0.47$ \\
Midbrain & $3.53 \pm 0.46$ & $3.57 \pm 0.42$ & $3.48 \pm 0.47$ & $3.36 \pm 0.52$ \\
Fore brain & $3.52 \pm 0.38$ & $3.51 \pm 0.52$ & $3.45 \pm 0.53$ & $3.4 \pm \pm 0.38$ \\
Otic system & $3.43 \pm 0.45$ & $3.54 \pm 0.48$ & $3.01 \pm 0.46^{\mathrm{a}}$ & $2.89 \pm 0.18^{\mathrm{a}}$ \\
Optic system & $2.65 \pm 0.34$ & $2.43 \pm 0.38$ & $2.12 \pm 0.52^{\mathrm{b}}$ & $1.68 \pm 0.44^{\mathrm{a}}$ \\
Olfactory system & $0.56 \pm 0.74$ & $0.48 \pm 0.46$ & $0.31 \pm 0.45^{\mathrm{b}}$ & $0.28 \pm 0.36^{\mathrm{a}}$ \\
Branchial bars & $3.32 \pm 0.48$ & $3.28 \pm 0.42$ & $2.89 \pm 0.36^{\mathrm{b}}$ & $2.67 \pm 0.31^{\mathrm{a}}$ \\
Maxillary process & $1.34 \pm 0.38$ & $1.27 \pm 0.46$ & $1.13 \pm 0.35$ & $1.03 \pm 0.28^{\mathrm{a}}$ \\
Mandibular process & $0.48 \pm 0.54$ & $0.43 \pm 0.47$ & $0.32 \pm 0.43$ & $0.06 \pm 0.01^{\mathrm{a}}$ \\
Forelimb & $1.98 \pm 0.01$ & $1.89 \pm 0.03$ & $1.73 \pm 0.05$ & $1.65 \pm 0.12^{\mathrm{a}}$ \\
Hindlimb & $1.95 \pm 0.02$ & $1.96 \pm 0.04$ & $1.84 \pm 0.08$ & $1.44 \pm 0.15^{\mathrm{a}}$ \\
\hline
\end{tabular}

Notes: Statistical differences between the groups were analyzed by Duncan's multiple range tests. Results are expressed as mean \pm SDM. ${ }^{a} p<0.05$, compared to pair-fed control and $250 \mathrm{mg} / \mathrm{kg}$. ${ }^{\mathrm{b}} p<0.05$ compared to the pair-fed control. 
a dose-dependent manner during post-treatment period but it was not statistically significant. The average maternal weight gain in the pair-fed control group and the $1000 \mathrm{mg}$ / $\mathrm{kg}$ A. aspera treated group from day 6-12 was $4.89 \pm 0.56$ $\mathrm{g}$ and $4.51 \pm 0.61 \mathrm{~g}$, respectively. The average maternal weight gain in the pair-fed control group and the $1000 \mathrm{mg} / \mathrm{kg}$ A. aspera treated group from day 6-20 was $16.32 \pm 0.62 \mathrm{~g}$ and $14.63 \pm 0.72 \mathrm{~g}$, respectively (Table 4).

\section{Outcomes of Pregnancy}

The number of fetuses was decreased in a dose-dependent manner. But it was not statistically significant. The implantation sites in pair-fed control and $1000 \mathrm{mg} / \mathrm{kg}$ treated groups were $8.23 \pm 0.71$ and $6.65 \pm 1.01$. Regarding the number of resorptions sites, there was significant increment in resorption sites in a high dose treated group as compared to the other groups. The number of live fetuses in pair-fed control and $1000 \mathrm{mg} / \mathrm{kg}$ groups was $8.67 \pm 0.89$ and $7.45 \pm 0.78$, respectively. There was significant increment in the number of dead fetuses in the $1000 \mathrm{mg} / \mathrm{kg}$ treated group as compared to pair-fed control group and $250 \mathrm{mg} / \mathrm{kg}$ treated group (Table 5).

\section{Growth of Fetus}

The litter weight of pair-fed control and $1000 \mathrm{mg} / \mathrm{kg}$ treated group was $2.91 \pm 0.15 \mathrm{~g}$ and $2.32 \pm 0.13 \mathrm{~g}$, respectively. There was significant reduction in litter weight in a high dose treated group as compared to pairfed control group. Similarly, the CRL of the fetus was significantly reduced in the $1000 \mathrm{mg} / \mathrm{kg}$ treated group. The CRL of pair-fed control and $1000 \mathrm{mg} / \mathrm{kg}$ treated groups was $2.82 \pm 0.17 \mathrm{~cm}$ and $2.31 \pm 0.1 \mathrm{~cm}$, respectively. The placental weight was significantly reduced in a high dose treated group (Table 6). However, there were no gross developmental malformations in the craniofacial, limb and vertebral column development, tail development or external genitalia.

\section{Discussion}

In the current study, the maternal weight gain and daily food intake were reduced in a dose-dependent manner, but it was not statistically significant among the groups. This finding is in agreement with a study conducted on toxicity of Achyranthes aspera which reveals that administration of the extracts at different doses does not produce any statistically significant changes in maternal body weight, food and water intake. ${ }^{36}$ But it was in contrast to the study conducted by Shibeshi et al which indicated that the mean body weight was significantly increased for the $1000 \mathrm{mg} / \mathrm{kg}$ Achyranthes aspera treated

Table 4 Daily Food Intakes and Maternal Weight Gains of Animals on Day-20 Achyranthes aspera Leaf Extract Experiment

\begin{tabular}{|l|l|l|l|l|l|}
\hline \multirow{2}{*}{ Group } & \multicolumn{3}{|c|}{ Daily Food Intake (g/day) } & \multicolumn{2}{c|}{ Maternal Weight Gain (g/day) } \\
\cline { 2 - 6 } & Day I-5 & Day 6-I 2 & Day 13-20 & Day 6-12 & Day 6-20 \\
\hline G-I & $14.23 \pm 0.25$ & $15.65 \pm 0.32$ & $17.53 \pm 0.35$ & $4.89 \pm 0.56$ & $16.32 \pm 0.62$ \\
G-II & $14.02 \pm 0.23$ & $15.49 \pm 0.12$ & $17.31 \pm 0.21$ & $5.07 \pm 0.47$ & $16.02 \pm 0.74$ \\
G-III & $14.12 \pm 0.24$ & $15.54 \pm 0.15$ & $17.21 \pm 0.08$ & $4.83 \pm 0.63$ & $14.84 \pm 0.46$ \\
G-IV & $14.07 \pm 0.16$ & $15.42 \pm 0.03$ & $17.11 \pm 0.04$ & $4.51 \pm 0.61$ & $14.63 \pm 0.72$ \\
F statistic & 2.05 & 7.31 & 67.12 & 10.54 & 72.25 \\
P value & 0.12 & $0.08 I$ & 0.061 & 0.082 & 0.064 \\
\hline
\end{tabular}

Table 5 Outcomes of Pregnancy of Day-20 Achyranthes aspera Leaf Extract Experiments

\begin{tabular}{|l|c|c|c|c|c|}
\hline \multirow{2}{*}{ Groups } & \multicolumn{5}{|c|}{ Outcomes of Pregnancy } \\
\cline { 2 - 6 } & $\begin{array}{c}\text { No. of } \\
\text { Fetuses }\end{array}$ & $\begin{array}{c}\text { Implantation } \\
\text { Sites }\end{array}$ & $\begin{array}{c}\text { Number of Resorptions/ } \\
\text { Litter }\end{array}$ & $\begin{array}{c}\text { Number of Live Fetuses/ } \\
\text { Dam }\end{array}$ & $\begin{array}{c}\text { Number of Dead Fetuses/ } \\
\text { Dam }\end{array}$ \\
\hline G-I & 44 & $8.23 \pm 0.7 I$ & $0.3 I \pm 0.43$ & $8.67 \pm 0.89$ & $0.35 \pm 0.65$ \\
G-II & 43 & $8.14 \pm 0.64$ & $0.33 \pm 0.41$ & $8.45 \pm 0.5 I$ & $0.37 \pm 0.47$ \\
G-III & 40 & $7.78 \pm 0.61$ & $0.34 \pm 0.44$ & $8.34 \pm 0.53$ & $0.4 I \pm 0.5 \mathrm{I}$ \\
G-IV & 39 & $6.65 \pm I .0 I^{\mathrm{a}}$ & $1.45 \pm 0.65^{\mathrm{a}}$ & $7.45 \pm 0.78^{\mathrm{a}}$ & $0.8 \mathrm{I} \pm 0.67^{\mathrm{a}}$ \\
F statistic & $0.9 \mathrm{I}$ & 2.33 & 3.6 & 3.23 & 0.84 \\
P value & 0.47 & 0.04 & $0.04 \mathrm{I}$ & 0.012 & 0.032 \\
\hline
\end{tabular}

Notes: Results are summarized as mean \pm SDM. ${ }^{a}$ Significantly different $(p<0.05)$ from pair-fed control group and $250 \mathrm{mg} / \mathrm{kg}$ treated group $($ ANOVA). 
Table 6 Growth of Fetus After Administration of Ethanolic Leaf Extracts of Achyranthes aspera on Day-20 Experiment

\begin{tabular}{|l|c|c|c|}
\hline \multirow{2}{*}{ Groups } & \multicolumn{3}{|c|}{ Growth of Fetus } \\
\cline { 2 - 4 } & $\begin{array}{c}\text { Litter Weight/ } \\
\text { Fetus (g) }\end{array}$ & $\begin{array}{c}\text { CRL/ } \\
\text { Fetus } \\
\text { (cm) }\end{array}$ & $\begin{array}{c}\text { Placental Weight/ } \\
\text { Fetus (g) }\end{array}$ \\
\hline G-I & $2.91 \pm 0.15$ & $2.82 \pm 0.17$ & $0.49 \pm 0.052$ \\
G-II & $2.89 \pm 0.12$ & $2.75 \pm 0.15$ & $0.48 \pm 0.06 \mathrm{I}$ \\
G-III & $2.67 \pm 0.14^{\mathrm{a}}$ & $2.78 \pm 0.14$ & $0.43 \pm 0.05$ \\
G-IV & $2.32 \pm 0.13^{\mathrm{a}}$ & $2.3 \mathrm{I} \pm 0.1 \mathrm{I}^{\mathrm{a}}$ & $0.41 \pm 0.043^{\mathrm{a}}$ \\
F statistic & 224.1 & 24.3 & 36.3 \\
P value & 0.03 & 0.023 & 0.021 \\
\hline
\end{tabular}

Notes: Results are summarized as mean \pm SDM. ${ }^{a}$ Significantly different $(p<0.05)$ from pair-fed control groups (ANOVA).

group. This disparity may be due to the extracts' different durations of administration. ${ }^{39}$

Compared to pair-fed control and $250 \mathrm{mg} / \mathrm{kg}$ treated groups, the count of implantation sites was significantly reduced in a high dose treated group. This result is comparable to earlier reports by Shibeshi et al who indicated that treating rats with a higher dose for 10 days postcoitally decreased the mean number of implantation sites significantly. In this study, treatment of rats with Achyranthes aspera leaf extracts showed a significant increase in the number of resorptions sites at high dose as compared to pair-fed control and $250 \mathrm{mg} / \mathrm{kg}$ treated groups. This may suggest that the extract has antiimplantation properties. ${ }^{39}$

The growth of embryos and fetuses was assessed by number of somites, morphological score, litter weight and CRL. The number of somites and morphological score were significantly reduced in a high dose treated group as compared to pair-fed control and $250 \mathrm{mg} / \mathrm{kg}$ treated groups. Similarly, the prenatal development indicators such as the litter weight and CRL were also significantly reduced in the $1000 \mathrm{mg} / \mathrm{kg}$ treated group as compared to other groups. Our result was comparable with the study conducted on contraceptive efficacy of Achyranthes aspera on mice which stated that treatment of animals with methanolic extract at a high dose $(1 \mathrm{~g} / \mathrm{kg})$ resulted in a significant reduction in the mean number of litters. ${ }^{39}$ Moreover, the number of live fetuses was significantly reduced in a high dose group while the number of dead fetuses was significantly increased in this group. This finding was in line with a report on the effect of $A$. aspera on fetal abortion, uterine and pituitary weights, serum lipids and hormones, which found that administering the methanolic extract at a high dose resulted in a significant change in the number of both live and dead fetuses, as well as a fetal survival percentage, indicating the possible abortifacient activity during pregnancy. ${ }^{26}$

Brown and Fabro's morphological scoring system was used to assess the development of embryonic systems at the end of organogenesis. ${ }^{38}$ At a dose of $1000 \mathrm{mg} / \mathrm{kg}$ of $A$. aspera leaf extracts, relative to the pair-fed control and $250 \mathrm{mg} / \mathrm{kg}$ treated groups, a statistically significant delay in embryonic development was observed. In the $1000 \mathrm{mg} / \mathrm{kg}$ group, significant delays were observed in development of the yolk sac circulation, optic, olfactory and otic systems. Moreover, the number of branchial bars and mandibular process were significantly reduced in the high dose treated group as compared to pair-fed control and $250 \mathrm{mg} / \mathrm{kg}$ treated groups. The development of forelimbs and hindlimbs was also significantly delayed in $1000 \mathrm{mg} / \mathrm{kg}$ treated embryos. This developmental delay may be due to the presence of alkaloids in Achyranthes aspera leaf extracts. ${ }^{40}$ However, there were no significant delays in the development of the primordial heart, central nervous system, forebrain, midbrain and hindbrain among the groups.

\section{Conclusion}

In conclusion, ethanolic leaf extract of $A$. aspera was found to have detrimental effects on the development of rat embryos and fetuses at a higher dose. Its teratogenic effects were supported by the significant delay in fetal and embryonic development, reduction in number of implantation sites and increment in fetal resorptions and fetal death. Moreover, administrations of ethanolic leaf extracts of A. aspera at a higher dose resulted in significant reduction in litter weights and CRL.

\section{Abbreviations}

A, Achyranthes; ANOVA, analysis of variance; CRL, crown-rump length; EPHI, Ethiopian Public Health Institute; OECD, Organization of Economic Cooperation and Development; SDM, standard deviation of mean.

\section{Data Sharing Statement}

The datasets used and/or analyzed during the current study are available from the corresponding author on reasonable request. 


\section{Ethics Approval}

This study was carried out after ethical clearance was obtained from College of Medicine and Health Sciences, Wollo University.

\section{Acknowledgments}

We are thankful to EPHI and Wollo University for providing all available materials for conducting the research.

\section{Funding}

There is no funding to report.

\section{Disclosure}

The authors declare that they have no conflicts of interest for this work.

\section{References}

1. Hung S-K, Ernst E. Herbal medicine: an overview of the literature from three decades. J Diet Suppl. 2010;7(3):217-226. doi:10.3109/ 19390211.2010.487818

2. Abramov V. Traditional medicine. World Health Org. 1996;134:1-3.

3. Bussmann RW, Glenn A, Meyer K, Kuhlman A, Townesmith A. Herbal mixtures in traditional medicine in Northern Peru. J Ethnobiol Ethnomed. 2010;6(1):1.

4. Abdullahi AA. Trends and challenges of traditional medicine in Africa. African $j$ Traditional Complementary Alternative Med. 2011;8:5S

5. Rodeiro I, Remírez-Figueredo D, García-Mesa M, Dorado P, LLerena A. Pharmacogenetics in Latin American populations: regulatory aspects, application to herbal medicine, cardiovascular and psychiatric disorders. Drug Metab Personalized Therapy. 2012;27 (1):57-60.

6. Mosihuzzaman M. Herbal medicine in healthcare-an overview. Nat Prod Commun. 2012;7(6):1934578X1200700628.

7. Kartal M. Intellectual property protection in the natural product drug discovery, traditional herbal medicine and herbal medicinal products. Phytotherapy Res. 2007;21(2):113-119.

8. Birhan W, Giday M, Teklehaymanot T. The contribution of traditional healers' clinics to public health care system in Addis Ababa, Ethiopia: a cross-sectional study. J Ethnobiol Ethnomed. 2011;7(1):1-7.

9. Desta B. Ethiopian traditional herbal drugs. Part III: anti-fertility activity of 70 medicinal plants. J Ethnopharmacol. 1994;44 (3):199-209.

10. Lusweti A, Wabuyele E, Ssegawa P, Mauremootoo J. Achyranthes aspera (Devil's horsewhip). Achyranthes Aspera. 2011.

11. Muthuswamy U, Sundaram D, Kuppusamy A, Varadharajan S, Puliyath J, Arumugam M. Anticataract and antioxidant activities of Achyranthes aspera Linn. against calcium-induced cataractogenesis using goat lenses. Der Pharmacia Lettre. 2012;4(2):436-442.

12. Shibeshil W, Makonnen E, Debella A, Zerihun L. Phytochemical, contraceptive efficacy and safety evaluations of the methanolic leaves extract of Achyranthes aspera L. Rats Pharmacol. 2006;3:217-224.

13. Rishikesh R, Mamun MR, Dutta PR, Maruf MA. Phytochemical and Pharmacological Investigation of Achyranthes Aspera Linn"e. Scholars Acad J Pharmacy. 2013;2(2):74-80.

14. Fikru A, Makonnen E, Eguale T, Debella A, Mekonnen GA. Evaluation of in vivo wound healing activity of methanol extract of Achyranthes aspera L. J Ethnopharmacol. 2012;143(2):469-474. doi:10.1016/j.jep.2012.06.049
15. Chinnasamy V, Subramaniyan V, Chandiran S, et al. Antiarthritic Activity of Achyranthes Aspera on Formaldehyde - Induced Arthritis in Rats. Open Access Maced J Med Sci. 2019;7 (17):2709-2714. doi:10.3889/oamjms.2019.559

16. Neeta SR, Jyoti B, Anjuvan S, Prabhjot K. Antibacterial potential of Achyranthus aspera Linn Procured from Himachal Pradesh, Punjab and Haryana, India. Res J Chem Sci ISSN. 2011;2231:606X.

17. Shendkar CD, Chandrachood PS, Pawar AB, Lavate SM, Deshpande NR. Quantitative estimation of macro, micro nutrients and trace elements by X-ray fluorescence spectroscopy (XRF) from Achyranthes aspera Linn. Magnesium. 2011;9630:0-963.

18. Dangi AS, Sharma M, Aparna JP. Antimicrobial activity of Achyranthus aspera Linn. Int J Pharm Biol Sci. 2012;1:1-6.

19. Elumalai EK, Chandrasekaran N, Thirumalai T, Sivakumar C, Therasa SV, David E. Achyranthes aspera leaf extracts inhibited fungal growth. Int J PharmTech Res. 2009;1(4):1576-1579.

20. Manjunatha BK, Abhilash N, Hegde V, Suchitra MN, Vidya SM. Hepatoprotective potency of Achyranthes aspera: an in-vivo study. Int J Pharm Phytopharmacol Res. 2012;1(6):387-390.

21. Zambare M, Bhosale UA, Somani RS, Yegnanarayan R, Talpate KA, Scholar R. Effect of Treatment with Achyranthes aspera (Agadha) ethanol extract on various hematological and biochemical parameters in alloxan induced diabetic rats. Int J Pharm Front Res. 2011;1(1):42-52.

22. Venkatalakshmi P, Vedha Valli N, Sangeetha S. Hypolipidemic effect of Achyranthes aspera on High fat diet induced atherogenic rats. Res J Pharmaceutical Biol Chem Sci. 2012;3(3):75.

23. Aurangabadkar M. In-vitro antioxidant activity of Achyranthes aspera L. J Pharmacy Res. 2009;2(9):1402-1403.

24. Uma B, Yegnanarayan R, Pophale P, Zambare M, Somani RS. Antinociceptive evaluation of an ethanol extract of Achyranthes aspera (agadha) in animal models of Nociception. Int J Phytomed. 2010;2(4):45.

25. Patil AG, Jobanputra AH. In-vitro antimicrobial activity of Achyranthes aspera stem extracts against oral pathogens. Asian Pac J Trop Biomed. 2012;1:1-4.

26. Shibeshi W, Makonnen E, Zerihun L, Debella A. Effect of Achyranthes aspera L. on fetal abortion, uterine and pituitary weights, serum lipids and hormones. Afr Health Sci. 2006;6 (2):108-112.

27. Sutar N, Alok DK, Soumya MK, Priyanka G, Susri MS. Diuretic activity of Achyranthes aspera leaves extracts. Int Res J Pharm. 2012;3:216-218.

28. Barua CC, Talukdar A, Begum SA, et al. Antidepressant-like effects of the methanolic extract of Achyranthes aspera Linn. in animal models of depression. Pharmacologyonline. 2009;2:587-594.

29. Mandefro B, Mereta ST, Tariku Y, Ambelu A. Molluscidal effect of Achyranthes aspera L. (Amaranthaceae) aqueous extract on adult snails of Biomphalaria pfeifferi and Lymnaea natalensis. Infect Dis Poverty. 2017;6(1):1-5.

30. Paul D, Bera S, Jana D, Maiti R, Ghosh D. In vitro determination of the contraceptive spermicidal activity of a composite extract of Achyranthes aspera and Stephania hernandifolia on human semen. Contraception. 2006;73(3):284-288.

31. Jain SK. Dictionary of Indian folk medicine and ethnobotany. 1991.

32. Vasudeva N, Sharma SK. Post-coital antifertility activity of Achyranthes aspera Linn. J Ethnopharmacol. 2006;107(2):179-181.

33. Hasan S. Pharmacological and medicinal uses of Achyranthes aspera. Int J Sci Environ Tech. 2014;3(1):123-129.

34. Debela A. Manual for Phytochemical Screening of Medicinal Plants. Addis Ababa, Ethiopia: EHNRI; 2002:26-71.

35. Guideline TT, Guideline O. OECD Guidelines for the Testing of Chemicals. J Med. 2001;420:1-14.

36. Reddy CV, Kamble A. Toxicity study of Achyranthus aspera. Int Lett Nat Sci. 2014;9.

37. Teshome D, Tiruneh C, Berihun G. Toxicity of Methanolic Extracts of Seeds of Moringa stenopetala, Moringaceae in Rat Embryos and Fetuses. Biomed Res Int. 2021;2021. 
38. Brown NA, Fabro S. Quantization of rat embryonic development in vitro: a morphological scoring system. Teratology. 1981;24 (1):65-78.

39. Shibeshil W, Makonnen E, Debella A, Zerihun L. Phytochemical, contraceptive efficacy and safety evaluations of the methanolic leaves extract of Achyranthes aspera L. Rats Pharmacol. 2006;3:217-224.
40. Green BT, Lee ST, Welch KD, Panter KE. "Plant alkaloids that cause developmental defects through the disruption of cholinergic neurotransmission,”. Birth Defects Res Part C. 2013;99(4):235-246.

\section{Publish your work in this journal}

The Journal of Experimental Pharmacology is an international, peerreviewed, open access journal publishing original research, reports, reviews and commentaries on all areas of laboratory and experimental pharmacology. The manuscript management system is completely online and includes a very quick and fair peer-review system. Visit $\mathrm{http} / / /$ www.dovepress.com/testimonials.php to read real quotes from published authors.

Submit your manuscript here: https://www.dovepress.com/journal-of-experimental-pharmacology-journal 